Pacific Journal of Mathematics

FOURIER-STIELTJES TRANSFORMS AND WEAKLY ALMOST
PERIODIC FUNCTIONAL FOR COMPACT GROUP 


\title{
FOURIER-STIELTJES TRANSFORMS AND WEAKLY ALMOST PERIODIC FUNCTIONALS FOR COMPACT GROUPS
}

\author{
Charles F. Dunkl and Donald E. Ramirez
}

\begin{abstract}
Let $G$ be a compact group and $H$ a closed subgroup. A function in the Fourier algebra of $H$ can be extended to a function in the Fourier algebra of $G$ without increase in norm and with an arbitrarily small increase in sup-norm. For $G$ a compact Lie group, the space of Fourier-Stieltjes transforms is not dense in the space of weakly almost periodic functionals on the Fourier algebra of $G$.
\end{abstract}

We let $G$ denote an infinite compact group and $\hat{G}$ its dual. We use the notation of [1, Chapters 7 and 8], [2], and [3]. Recall $A(G)$ denotes the Fourier algebra of $G$ (an algebra of continuous functions on $G$ ), and $\mathscr{L}^{\infty}(\hat{G})$ denotes its dual space under the pairing $\langle f, \phi\rangle$ $\left(f \in A(G), \phi \in \mathscr{L}^{\infty}(\hat{G})\right)$. Further, note $\mathscr{L}^{\infty}(\hat{G})$ is identified with the $C^{*}$-algebra of bounded operators on $L^{2}(G)$ commuting with right translation. The module action of $A(G)$ on $\mathscr{L}^{\infty}(\widehat{G})$ is defined by the following: for $f \in A(G), \phi \in \mathscr{L}^{\infty}(\widehat{G}), f \cdot \phi \in \mathscr{L}^{\infty}(\widehat{G})$ by $\langle g, f \cdot \phi\rangle=$ $\langle f g, \phi\rangle, g \in A(G)$. Also $\|f \cdot \phi\|_{\infty} \leqq\|f\|_{A}\|\phi\|_{\infty}$.

Let $\phi \in \mathscr{L}^{\infty}(\hat{G})$. We call $\phi$ a weakly almost periodic functional if and only if the map $f \mapsto f \cdot \phi$ from $A(G)$ to $\mathscr{L}^{\infty}(\widehat{G})$ is a weakly compact operator. The space of all such is denoted by $W(\widehat{G})$.

Let $M(G)$ denote the measure algebra of $G$. For $\mu \in M(G)$, the Fourier-Stieltjes transform of $\mu, \mathscr{F} \mu$, is a matrix-valued function in $\mathscr{L}^{\infty}(\hat{G})$ defined for $\alpha \in \hat{G}$ by

$$
\alpha \mapsto(\mathscr{F} \mu)_{\alpha}=\int_{G} T_{\alpha}\left(x^{-1}\right) d \mu(x) \quad\left(T_{\alpha} \in \alpha\right) .
$$

We denote the closure of $\mathscr{F} M(G)$ in $\mathscr{L}^{\infty}(\hat{G})$ by $\mathscr{L C}(\hat{G})$. In [2], we showed that $W(\hat{G})$ is a closed subspace of $\mathscr{L}^{\infty}(\widehat{G})$, and that $\mathscr{M}(\widehat{G}) \subset$ $W(\widehat{G})$ with the inclusion proper when $G$ is a direct product of an infinite collection of nontrivial compact groups. In this paper, we show the inclusion is proper for all compact Lie groups.

We first state a standard lemma.

Lemma 1. Let $A, B$ be compact subsets of a topological group $G$. Suppose $A B \subset U, U$ an open subset of $G$. Then there is an open neighborhood $V$ of the identity $e$ of $G$ such that $A V B \subset U$. 
Proposition 2. Let $G$ be a compact group and $H$ a closed subgroup. Let $W$ be an open subset of $G$ with $H \cap \bar{W}=\varnothing$. Then there is a continuous positive definite function $p$ on $G$ with $p(x)=1, x \in$ $H$, and $p(x)=0, x \in W$. (Note $p \in A(G)$ and $\|p\|_{A}=1$.)

Proof. Let $U$ be an open subset of $G$ with $H \subset U$, and $U \cap W=$ $\varnothing$. Choose $V_{1}$ an open neighborhood of $e$ with $H V_{1} H \subset U$. Now let $V$ be an open neighborhood of $e$ with $V V \subset V_{1}$ and $V=V^{-1}$. Thus $H V V H \subset H V_{1} H \subset U$.

Let $p=\left(m_{G}(H V)\right)^{-1} \chi_{H V}{ }^{*} \chi_{V H}\left(m_{G}\right.$ is normalized Haar measure on $G$ and $\chi_{A}$ denotes the characteristic function of $A$ ). Then $p(x)=$ $\left(m_{G}(H V)\right)^{-1} m_{G}(x H V \cap H V), x \in G$. Thus for $x \in H, p(x)=1$. If $p(x) \neq$ 0 , then $x H V \cap H V \neq \varnothing$, and so $x \in H V V H \subset U$.

THEOREM 3. Let $G$ be a compact group and $H$ a closed subgroup. Let $f \in A(H)$ and $\varepsilon>0$. Then there exists $g \in A(G),\|g\|_{A}=\|f\|_{A}$, $g \mid H=f$, and $\|g\|_{\infty} \leqq\|f\|_{\infty}+\varepsilon$.

Proof. Let $h$ be an extension of $f$ to $G$ with $\|h\|_{A}=\|f\|_{A}$ (see [1, Chapter 8]). Let $V=\left\{x \in G:|h(x)|>\|f\|_{\infty}+\varepsilon\right\}$. Now let $p$ be as in Proposition 2, and let $g=p h$.

We now state a characterization of $\mathscr{L}(\hat{G})$. The proof for abelian groups is in [1, Chapter 3]. The proof for nonabelian groups is analogous.

THEOREM 4. Let $G$ be a compact group and $\phi \in \mathscr{L}^{\infty}(\widehat{G})$. For $\phi \epsilon$ $\mathscr{L}(\hat{G})$ it is necessary and sufficient that whenever $\left\{f_{n}\right\}$ is a sequence from $A(G)$ with $\left\|f_{n}\right\|_{A} \leqq 1$ and $\left\|f_{n}\right\|_{\infty} \stackrel{n}{\longrightarrow} 0$ we have $\left\langle f_{n}, \phi\right\rangle \stackrel{n}{\longrightarrow} 0$.

Theorem 5. Let $G$ be a compact Lie group. Then $\mathscr{M}(\widehat{G}) \neq$ $W(\widehat{G})$.

Proof. Let $H$ be a total subgroup of $G$; that is, $H$ is the circle group. Now $\mathscr{C}(\hat{H}) \neq W(\hat{H})$, (see [1, Chapter 4]).

Let $\pi_{1}$ denote the restriction map of $A(G)$ onto $A(H)$ and let $\hat{\pi}$ denote the adjoint map of $\mathscr{L}^{\infty}(\hat{H})$ into $\mathscr{L}^{\infty}(\hat{G})$. In [3], we showed that

$$
\hat{\pi} \mathscr{L}(\hat{H}) \subset \mathscr{M}(\hat{G}) \text { and } \hat{\pi} W(\hat{H}) \subset W(\hat{G}) .
$$

Let $\phi \in W(\hat{H}) \backslash \mathscr{C}(\hat{H})$. Now $\hat{\pi} \phi \in W(\hat{G})$ so we need only show that $\hat{\pi} \phi \notin \mathscr{L}(\hat{G})$. Since $\phi \notin \mathscr{M}(\hat{H})$, there is a sequence $\left\{f_{n}\right\} \subset A(H),\left\|f_{n}\right\|_{A} \leqq$ $1,\left\|f_{n}\right\|_{\infty} \stackrel{n}{\longrightarrow} 0$ with $\left|\left\langle f_{n}, \phi\right\rangle\right| \geqq \varepsilon$ (some $\varepsilon>0$ ). Extend $f_{n}$ to $g_{n} \in$ 
$A(G)$ by Theorem 3 with $\left\|g_{n}\right\|_{A} \leqq 1$ and $\left\|g_{n}\right\|_{\infty} \stackrel{n}{\longrightarrow} 0$. But $\left\langle g_{n}, \hat{\pi} \phi\right\rangle=$ $\left\langle\pi_{1} g_{n}, \phi\right\rangle=\left\langle f_{n}, \phi\right\rangle$, and so $\hat{\pi} \phi \notin \mathscr{C}(\hat{G})$.

REMARK. If a compact group $G$ has a closed subgroup $H$ with $\mathscr{L}(\hat{H}) \neq W(\hat{H})$, then $\mathscr{M}(\hat{G}) \neq W(\hat{G})$, (in particular, if $G$ contains an infinite abelian subgroup). Indeed, it is an open question whether an infinite compact group always contains an infinite abelian subgroup.

CoROLlaRY 6. Let $G$ be a compact group with $H$ a closed subgroup. Then

$$
\hat{\pi}(W(\hat{H}) \backslash \mathscr{L}(\hat{H})) \subset W(\hat{G}) \backslash \mathscr{L}(\hat{G}) \cdot
$$

\section{REFERENCES}

1. C. Dunkl and D. Ramirez, Topics in Harmonic Analysis, Appleton-Century-Crofts, New York, 1971.

2. Weakly almost periodic functionals on the Fourier algebra, Trans. Amer. Math. Soc., (1972).

3. - Weakly almost periodic functionals carried by hypercosets, Trans. Amer. Math. Soc., 164 (1972).

Received November 18, 1970. This research was supported in part by NSF contract number GP-19852.

UNIVERSITY OF VIRGINIA 



\title{
PACIFIC JOURNAL OF MATHEMATICS
}

\author{
EDITORS
}

\author{
H. SAMELSON \\ Stanford University \\ Stanford, California 94305 \\ C. R. HOBBY \\ University of Washington \\ Seattle, Washington 98105
}

J. DugundJI

Department of Mathematics

University of Southern California

Los Angeles, California 90007

RICHARD ARENS

University of California

Los Angeles, California 90024

\section{ASSOCIATE EDITORS}
E. F. BeCKenBaCH
B. H. NeUMANN
F. WOLF
K. Yoshida

\section{SUPPORTING INSTITUTIONS}

\author{
UNIVERSITY OF BRITISH COLUMBIA \\ CALIFORNIA INSTITUTE OF TECHNOLOGY \\ UNIVERSITY OF CALIFORNIA \\ MONTANA STATE UNIVERSITY \\ UNIVERSITY OF NEVADA \\ NEW MEXICO STATE UNIVERSITY \\ OREGON STATE UNIVERSITY \\ UNIVERSITY OF OREGON \\ OSAKA UNIVERSITY
}

\author{
UNIVERSITY OF SOUTHERN CALIFORNIA \\ STANFORD UNIVERSITY \\ UNIVERSITY OF TOKYO \\ UNIVERSITY OF UTAH \\ WASHINGTON STATE UNIVERSITY \\ UNIVERSITY OF WASHINGTON \\ AMERICAN MATHEMATICAL SOCIETY \\ NAVAL WEAPONS CENTER
}

The Supporting Institutions listed above contribute to the cost of publication of this Journal, but they are not owners or publishers and have no responsibility for its content or policies.

Mathematical papers intended for publication in the Pacific Journal of Mathematics should be in typed form or offset-reproduced, (not dittoed), double spaced with large margins. Underline Greek letters in red, German in green, and script in blue. The first paragraph or two must be capable of being used separately as a synopsis of the entire paper. The editorial "we" must not be used in the synopsis, and items of the bibliography should not be cited there unless absolutely necessary, in which case they must be identified by author and Journal, rather than by item number. Manuscripts, in duplicate if possible, may be sent to any one of the four editors. Please classify according to the scheme of Math. Rev. Index to Vol. 39. All other communications to the editors should be addressed to the managing editor, Richard Arens, University of California, Los Angeles, California, 90024.

50 reprints are provided free for each article; additional copies may be obtained at cost in multiples of 50 .

The Pacific Journal of Mathematics is published monthly. Effective with Volume 16 the price per volume (3 numbers) is $\$ 8.00$; single issues, $\$ 3.00$. Special price for current issues to individual faculty members of supporting institutions and to individual members of the American Mathematical Society: $\$ 4.00$ per volume; single issues $\$ 1.50$. Back numbers are available.

Subscriptions, orders for back numbers, and changes of address should be sent to Pacific Journal of Mathematics, 103 Highland Boulevard, Berkeley, California, 94708.

PUBLISHED BY PACIFIC JOURNAL OF MATHEMATICS, A NON-PROFIT CORPORATION

Printed at Kokusai Bunken Insatsusha (International Academic Printing Co., Ltd.), 270, 3chome Totsuka-cho, Shinjuku-ku, Tokyo 160, Japan. 


\section{Pacific Journal of Mathematics}

\section{Vol. 39, No. $3 \quad$ July, 1971}

William O'Bannon Alltop, 5-designs in affine spaces ................... 547

B. G. Basmaji, Real-valued characters of metacyclic groups ................. 553

Miroslav Benda, On saturated reduced products....................... 557

J. T. Borrego, Haskell Cohen and Esmond Ernest Devun, Uniquely representable semigroups. II.......................................

George Lee Cain Jr. and Mohammed Zuhair Zaki Nashed, Fixed points and stability for a sum of two operators in locally convex spaces ....................

Donald Richard Chalice, Restrictions of Banach function spaces ...............

Eugene Frank Cornelius, Jr., A generalization of separable groups ..............

Joel L. Cunningham, Primes in products of rings ......................

Robert Alan Morris, On the Brauer group of $Z$.

593

603

615

David Earl Dobbs, Amitsur cohomology of algebraic number rings ...............

Charles F. Dunkl and Donald Edward Ramirez, Fourier-Stieltjes transforms and

weakly almost periodic functionals for compact groups ...................

Hicham Fakhoury, Structures uniformes faibles sur une classe de cônes et

d'ensembles convexes ......................................

Leslie R. Fletcher, A note on C $\theta \theta$-groups.

Humphrey Sek-Ching Fong and Louis Sucheston, On the ratio ergodic theorem for

semi-groups............................................

James Arthur Gerhard, Subdirectly irreducible idempotent semigroups ...........

Thomas Eric Hall, Orthodox semigroups.....................

Marcel Herzog, $C \theta \theta$-groups involving no Suzuki groups ..........

669

687

John Walter Hinrichsen, Concerning web-like continua ..........

691

Frank Norris Huggins, A generalization of a theorem of F. Riesz.

695

Carlos Johnson, Jr., On certain poset and semilattice homomorphisms

703

Alan Leslie Lambert, Strictly cyclic operator algebras ...........

717

Howard Wilson Lambert, Planar surfaces in knot manifolds . . .

727

Robert Allen McCoy, Groups of homeomorphisms of normed linear spaces ....... 735

T. S. Nanjundiah, Refinements of Wallis's estimate and their generalizations ...... 745

Roger David Nussbaum, A geometric approach to the fixed point index .......... 751

John Emanuel de Pillis, Convexity properties of a generalized numerical range .... 767

Donald C. Ramsey, Generating monomials for finite semigroups ....

783

William T. Reid, A disconjugacy criterion for higher order linear vector differential equations...

Roger Allen Wiegand, Modules over universal regular rings...

Kung-Wei Yang, Compact functors in categories of non-archimedean Banach

spaces.

R. Grant Woods, Correction to: "Co-absolutes of remainders of Stone-Čech compactifications".

Ronald Owen Fulp, Correction to: "Tensor and torsion products of

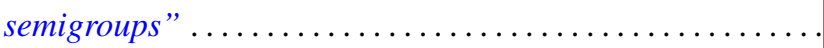

Bruce Alan Barnes, Correction to: "Banach algebras which are ideals in a banach 